\title{
Pioderma gangrenoso asociado a artritis reumatoide
}

\author{
Pyoderma gangrenosum associated \\ with rheumatoid arthritis
}

\author{
Juan Ramón Trejo-Acuña, ${ }^{*}$ Armando Medina-Bojórquez, ${ }^{\text {} ~ J o s e ́ ~ A l b e r t o ~ R a m o s-G a r i b a y, ~}{ }^{\ddagger}$ \\ Larissa Margarita Zárate-Flores, $\$$ María Fernanda Santos-Ortíz
}

RESUMEN

\begin{abstract}
El pioderma gangrenoso es una dermatosis inflamatoria que forma parte de las dermatosis neutrofílicas, en más de la mitad de los casos se asocia a alguna enfermedad sistémica. Se comunica el caso de un hombre de 52 años de edad con dermatosis diseminada a tronco anterior y posterior, tercio inferior de miembros superiores e inferiores. La dermatosis estaba constituida por numerosas úlceras de diversas formas, algunas de ellas de más de $10 \mathrm{~cm}$ de diámetro, de fondo limpio, bordes socavados y eritematovioláceas. Los hallazgos histopatológicos fueron compatibles con el pioderma gangrenoso. Se estableció el diagnóstico clínico de variedad ulcerosa diseminada asociado a artritis reumatoide.
\end{abstract}

Palabras clave: Pioderma gangrenoso, dermatosis neutrofílica, artritis reumatoide.

\section{ABSTRACT}

Pyoderma gangrenosum is an inflammatory dermatosis that is part of neutrophilic dermatoses, in more than half of the cases it has been associated with some systemic disease. We present the case of a 52-yearold man with disseminated dermatosis to the anterior and posterior trunk, the lower third of the upper limbs and the lower third of the lower limbs is reported. The dermatosis consisted of numerous ulcers of various shapes, some of them larger than $10 \mathrm{~cm}$ in diameter, with a clean bottom, undercut edges and purplish erythematous. Histopathological findings were consistent with pyoderma gangrenosum. The clinical diagnosis of a disseminated ulcer variety associated with rheumatoid arthritis was established.

Keywords: Pyoderma gangrenosum, neutrophilic dermatosis, rheumatoid arthritis.

\section{INTRODUCCIÓN}

El pioderma gangrenoso (PG) es una dermatosis neutrofílica (DN) poco común, caracterizada por la presencia de úlceras dolorosas de rápida evolución, con bordes necróticos y eritema periférico. El término PG está mal empleado, ya que no es un proceso infeccioso, ni una entidad necrótica clásica.

\footnotetext{
* Dermatooncólogo adscrito.

₹ Subjefe del Servicio de Dermatopatología.

$\S$ Residente del cuarto año de Dermatología.

" Residente del segundo año de Dermatología.

Centro Dermatológico «Dr. Ladislao de la Pascua», SSCDMX. México.
}

La enfermedad puede presentarse con una o varias lesiones de aparición simultánea. Los pacientes con PG pueden tener enfermedad crónica, recurrente o autorresolutiva. ${ }^{1}$

Fue descrita por primera vez por el dermatólogo francés Louis-Anne-Jean Brocq en 1908, quien acuñó el término phagédénisme géométrique (fagedenismo geométrico) haciendo referencia a una rápida extensión de úlceras hasta el tejido celular subcutáneo. En 1930, Brunsting designó el nombre que usamos en la

Citar como: Trejo-Acuña JR, Medina-Bojórquez A, Ramos-Garibay JA, Zárate-Flores LM, Santos-Ortíz MF. Pioderma gangrenoso asociado a artritis reumatoide. Rev Cent Dermatol Pascua. 2021; 30 (3): 148-155. https://dx.doi.org/10.35366/103829 
actualidad. A pesar de que el término es incorrecto, la clásica descripción de su presentación, comportamiento y las condiciones asociadas, forman la base del pensamiento y abordaje actuales, motivo por el cual continúa denominándose PG. Una de las observaciones más relevantes hechas por Brunsting, fue la del fenómeno de patergia, documentando la formación de una reacción inflamatoria de la piel con disrupción epidérmica ante traumatismo mínimo. ${ }^{1}$

Más de la mitad de los pacientes con PG son asociados con enfermedades sistémicas al momento del diagnóstico, siendo las más frecuentes la enfermedad inflamatoria intestinal, la artritis reumatoide y las neoplasias hematológicas. ${ }^{2}$

La frecuencia e incidencia del pioderma gangrenoso en México es desconocida; sin embargo, se ha estimado entre tres y 10 pacientes por millón de habitantes por año. El pico de incidencia es entre los 20 y 50 años, predominando en el sexo femenino. ${ }^{3}$

\section{Patogenia}

Si bien la patogenia del PG aún no ha sido descrita por completo, algunos estudios sugieren que la disfunción de los neutrófilos y la inflamación sistémica aberrante juegan un papel vital en la inducción de las lesiones del PG. ${ }^{2}$ EI PG es el prototipo de las dermatosis neutrofílicas; éstas se componen de un grupo de alteraciones cutáneas caracterizadas histopatológicamente por un infiltrado inflamatorio neutrofílico sin presencia de vasculitis ni de proceso infeccioso. ${ }^{1}$ Representa un patrón de reacción complejo con múltiples vías, o la convergencia de varias características que favorecen la presentación y curso heterogéneos de la enfermedad. La disregulación del sistema inmunológico innato, así como la quimiotaxis anormal, la migración de neutrófilos, la fagocitosis, la capacidad bactericida y el tráfico anormal de neutrófilos participan en la fisiopatogenia. Los factores que contribuyen a las manifestaciones clínicas del PG incluyen la disfunción de los neutrófilos, las mutaciones genéticas y la inflamación anormal. ${ }^{4}$

El traumatismo es el factor mejor documentado como inductor de PG. Se piensa que estimula la expresión de IL-36, citocina conocida por tener un papel importante en la fisiopatología del PG. De igual forma, los traumatismos mínimos pueden aumentar la expresión de IL-8, también importante en la fisiopatología del PG. El daño tisular puede causar la liberación de autoantígenos. Este conjunto de eventos suele ser suficiente para inducir PG. ${ }^{1}$
Clínicamente, las úlceras del PG tienen un borde socavado característico creado por un denso infiltrado inflamatorio neutrofílico, el cual destruye la dermis subyacente, dejando viable la epidermis sobresaliente, pero con aporte sanguíneo comprometido. A medida que la inflamación se expande, la epidermis central se necrosa, revelando la úlcera subyacente. La ubicación profunda de las células inflamatorias da al borde de la lesión su característico aspecto rojizo violáceo. La base de la úlcera suele ser muy exudativa, debido al denso infiltrado neutrofílico. En la periferia del borde, hay una zona de eritema que en la histopatología revela infiltrado perivascular. Se ha identificado la expresión diferencial de numerosos genes en el PG, incluidos muchos del sistema inmunológico innato. Los queratinocitos son con seguridad una fuente importante de citocinas proinflamatorias IL-1 $\alpha$, IL-1 $\beta$, IL-8, IL-36 y factor de necrosis tumoral (TNF), todas ellas promueven el reclutamiento de neutrófilos, en especial de IL-8, la cual es un factor mayor de quimiotaxis neutrofílico. ${ }^{1}$

La característica de la enfermedad de ser autorresolutiva es de interés; no obstante, los mecanismos por los cuales ocurre esto son inciertos. Además de las citocinas antes comentadas en la patogenia de la enfermedad, se ha visto que la presencia de IL-10 puede bloquear la actividad del $\mathrm{FN}-\mathrm{K} \beta$, inhibiendo la expresión de citocinas asociadas a la respuesta $\mathrm{TH} 1$, llevando a una alteración de la expresión del complejo mayor de histocompatibilidad, también la respuesta de las células T reguladoras se encuentra alterada; éstos podrían ser algunos de los factores por los cuales las lesiones remiten eventualmente. ${ }^{1}$

\section{Cuadro clínico}

Las manifestaciones clínicas del PG clásico afectan sobre todo a las extremidades inferiores, aunque la bibliografía describe que puede localizarse en cualquier topografía. Esta dermatosis inicia con frecuencia como una mancha eritematosa, que progresa con rapidez, con posterior formación de vesícula, ulceración o necrosis; color eritematovioláceo, de bordes irregulares y en extremo dolorosa. Es frecuente que las lesiones sean diagnosticadas como úlceras que no cicatrizan, sometiendo a los pacientes a desbridamiento, el cual puede provocar deterioro de la afección a través del fenómeno de patergia. ${ }^{5}$

La mayoría de los casos de PG son del tipo clásico, reportado en $85 \%$ de los casos, existen otros subtipos descritos en la literatura, que incluyen las variedades: ampollosa, pustulosa, vegetante/granulosa superficial, periestomal y maligna. ${ }^{5}$ 
PG ampolloso: se presenta de manera característica en cara y extremidades superiores; como vesículas superficiales, dolorosas de rápida evolución y ampollas que surgen en brotes, a menudo confluentes, que tienden a ulcerarse. Histológicamente esto comparte similitudes con el síndrome de Sweet. Se debe buscar una neoplasia hematológica, ya que se identifican hasta en $70 \%$ de los casos. ${ }^{1}$

PG pustuloso: suele aparecer en piernas y tronco; constituido por pústulas simétricas con bordes eritematosos. Esta forma se observa con mayor frecuencia asociada a enfermedad inflamatoria intestinal dilatada. ${ }^{6}$

PG superficial granulomatoso: conocido como PG vegetante, este subtipo en general es de progresión lenta y se presenta con lesiones verrugosas y ulceradas. Estos pacientes tienen menos probabilidades de desarrollar una afección sistémica subyacente y, por lo general, no requieren tratamiento sistémico. ${ }^{7}$

PG periestomal: esta variante tal vez sea el resultado de una respuesta patérgica al trauma por irritación fecal o secundaria a aparatología en la piel y se observa con mayor frecuencia en el contexto de estomas en pacientes con enfermedad inflamatoria intestinal. Está constituido por pápulas que se erosionan y se convierten en úlceras de bordes mal definidos, difícil de diferenciar de otras lesiones erosivas periestomales. ${ }^{1}$

Pioderma maligno: ésta es una variedad clínica importante pero poco frecuente, la cual se presenta como ulcerada destructiva que típicamente afecta la parte superior del tronco, cabeza y cuello. Las lesiones no muestran bordes violáceos, además de no asociarse a enfermedad sistémica. ${ }^{1}$

\section{Histopatología}

Los hallazgos histopatológicos no son característicos de PG; en las lesiones iniciales aparece una reacción vascular neutrofílica que puede ser foliculocéntrica. Los infiltrados neutrofílicos se observan en las lesiones activas, con necrosis central, ulceración de la epidermis y escaso infiltrado mononuclear más periférico, engrosamiento del endotelio capilar, hemorragia y coagulación. Los hallazgos histopatológicos también dependen del sitio de la biopsia (borde, centro o área necrótica de la úlcera), el estadio de progresión y la variedad de la enfermedad (vegetante, ampollosa, ulcerosa o pustulosa). ${ }^{8}$

\section{Asociaciones}

El PG puede ocurrir de forma aislada, como un síndrome inflamatorio hereditario, en asociación a una enfermedad sistémica, y con o sin manifestaciones

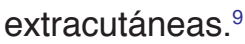

Kridin y colaboradores publicaron en el 2018 un metaanálisis en el cual se reportó que $57 \%$ de los pacientes con PG tenían una enfermedad sistémica asociada, siendo las más frecuentes: enfermedad inflamatoria intestinal, artritis reumatoide y neoplasias malignas hematológicas. ${ }^{10}$

Aproximadamente, $13 \%$ de los pacientes con PG tienen artritis inflamatoria, la más común es la artritis reumatoide (AR). La asociación entre $P G$ y $A R$ se investigó en un estudio reciente de casos y controles que reveló que la prevalencia de por vida de la AR era mayor entre los pacientes con PG que en los controles, y que la $A R$ aumenta las probabilidades de desarrollar PG en más de tres veces. Además de la $A R$, se ha informado de PG en pacientes con espondiloartritis, como artritis psoriásica, espondilitis anquilosante y artritis asociada a enfermedad inflamatoria intestinal. ${ }^{9}$

Sawka y colaboradores realizaron una revisión sistemática en donde el objetivo fue describir la asociación entre PG y AR. Consideraron 1,399 artículos, encontrando 129 pacientes con $P G$ y artritis inflamatorias. La AR se presentó en $50.4 \%$ de los casos (65 pacientes). En la mayoría, el dolor articular precedía a la aparición de PG, con una media de 10 años. Dentro de las características sociodemográficas se descubrió que, de la totalidad de pacientes, $76.7 \%$ eran mujeres y $23.3 \%$ hombres; la media de edad fue de 49 años; en la mayor parte de los casos (55.8\%), al momento del diagnóstico se desconocía el tiempo de evolución del PG; la topografía más frecuente del PG fue extremidad inferior (67.4\%), seguido de tobillo/pie (24.8\%), la aparición de la AR fue en su mayor parte posterior al PG $(76 \%){ }^{9}$

\section{DIAGNÓSTICO}

Establecer el PG puede ser un desafío debido a la presentación variable de la patología, la superposición clínica con otras condiciones y la ausencia de hallazgos histopatológicos patognomónicos. Clásicamente el PG es determinado por exclusión, lo que amerita descartar todas las causas posibles de úlcera. ${ }^{1} \mathrm{~A}$ pesar de no existir criterios estandarizados, se han propuesto algunos procedimientos. El primero llamado PARACELSUS $P G$, utiliza una escala de puntaje con criterios mayores y menores, siendo necesarios dos mayores y uno menor para el diagnóstico; los criterios se basaban en la prevalencia de hallazgos poblacionales en PG; requiriendo dos criterios mayores y dos menores (Tabla 1). ${ }^{5}$ El segundo procedimiento consta de criterios internacionales, 
los cuales requieren uno mayor y cuatro menores para establecer el diagnóstico (Tabla 2). ${ }^{5}$

\section{Diagnóstico diferencial}

No existen marcadores serológicos específicos para PG, y la histopatología es inespecífica y variable, dependiendo del subtipo de PG y el estadio de la enfermedad, porque hay un número amplio de diagnósticos diferenciales a considerar. ${ }^{3}$ Dentro de esa amplia variedad encontramos procesos infecciosos como micosis profundas, protozoarios, infecciones bacterianas y víricas; enfermedades autoinmunes y vasculitis como enfermedad de Behcet o lupus; dermatosis neutrofílicas como el síndrome de Sweet; vasculares como la úlcera de Martorell, entre muchos otros más. ${ }^{4}$

Por lo tanto, hay un sinfín de trastornos a considerar, siendo una parte importante del protocolo de estudio excluir todos los posibles diagnósticos diferenciales. ${ }^{3}$

\section{TRATAMIENTO}

El tratamiento del PG continúa siendo anecdótico, con sólo dos estudios controlados aleatorizados, series de casos y publicaciones con poca evidencia. No existen guías nacionales o internacionales para su manejo, por lo que éste se basa en el control de la enfermedad, dependiendo de su gravedad y extensión. ${ }^{5}$

Ante la falta de terapéutica estandarizada se han propuesto manejos con base en la opinión de expertos.

Primero, hay que tener presente que el PG es una enfermedad inmunomediada. Por lo tanto, el objetivo principal de la terapia es detener el proceso inflamatorio aberrante, y este objetivo se logra en general con fármacos inmunosupresores. ${ }^{1}$ Los corticosteroides tópicos potentes y los inhibidores de la calcineurina (como el ta-

Tabla 1: Herramienta diagnóstica para pioderma gangrenoso.

\section{Criterios mayores}

Progresión rápida de una úlcera necrótica cutánea con bordes irregulares, violáceos mal definidos

Otras causas de úlcera cutánea excluidas

Criterios menores

Antecedentes de patergia o cicatrices clínicamente cribiformes Enfermedad sistémica asociada (enfermedad inflamatoria intestinal, artritis, gammapatía IgA o malignidad subyacente) Hallazgos histopatológicos clásicos

Respuesta al tratamiento (respuesta rápida al tratamiento con esteroides sistémicos - 50\% de mejoría en un mes)
Tabla 2: Herramienta diagnóstica mejorada para pioderma gangrenoso.

\section{Criterios mayores}

Biopsia del borde de la úlcera que demuestra infiltrado neutrofilico

\section{Criterios menores}

Proceso infeccioso descartado

Fenómeno de patergia

Antecedente de enfermedad inflamatoria

intestinal 0 artritis reumatoide

Antecedente de pápula, pústula o vesícula ulcerada

dentro de los primeros 4 días de aparición

Eritema periférico, borde mal definido y dolor a

la palpación en el sitio de la ulceración

Múltiples úlceras, de las cuales al menos

una en cara anterior de pierna

Cicatrices cribiformes o de "papel arrugado»

en los sitios de úlceras cicatrizadas

Disminución del tamaño de la úlcera en el plazo de un

mes después de iniciar tratamiento inmunosupresor

crolimus) aplicados a la superficie de la úlcera son útiles; se pueden considerar las inyecciones intralesionales de corticosteroides en el borde activo eritematoso. En estadios severos de la enfermedad se requiere terapia sistémica. Los corticosteroides orales $(0.5$ a $1 \mathrm{mg} / \mathrm{kg} /$ día) son la base del tratamiento y se utilizan para lograr control rápido de la patología. Se pueden utilizar algunos inmunomoduladores como ahorradores de esteroides, en casos que se requiera tratamiento prolongado. ${ }^{5} \mathrm{En}$ la actualidad existe un creciente cuerpo de evidencia para apoyar la terapia biológica como tratamiento del PG, el cual se encuentra dirigido contra varias citocinas; con todo, no existe consenso sobre si estos tratamientos deben administrarse sólo cuando otros han fallado o como terapias de primera línea en PG severos. ${ }^{1}$ Hasta ahora, el infliximab ha sido el biológico con mayor evidencia para respaldar su uso temprano en PG. Adalimumab ha demostrado eficacia para lograr la cicatrización de heridas en casos recalcitrantes, y hay algunos reportes de casos que demuestran éxito con etanercept, ustekinumab, anakinra y canakinumab. ${ }^{5}$

En segundo lugar, el PG es una enfermedad ulcerosa que requiere cuidado adecuado de las heridas. Sin importar la causa, las heridas pueden tardar en cicatrizar y, por lo tanto, se debe seguir un régimen estricto de limpieza y vendaje. ${ }^{1}$ Es indispensable optimizar el cuidado local de las lesiones, en especial en casos de PG localizados en extremidades inferiores, donde la cicatrización puede comprometerse por enfermedad vascular. La terapia de apoyo con apósitos adecua- 
dos, compresión (de haberse descartado insuficiencia arterial), así como adecuada analgesia son esenciales para optimizar la cicatrización. ${ }^{5}$

En tercer lugar, las enfermedades asociadas con PG contribuyen a la capacidad de curación del paciente. Las enfermedades asociadas deben tenerse en cuenta cuando se diseña una estrategia de tratamiento. ${ }^{1}$

En cuarto lugar, el PG se relaciona con dolor considerable y problemas psicosociales. Estos problemas deben abordarse temprano con educación y, cuando sea necesario, derivaciones apropiadas a clínicas de psiquiatría y manejo del dolor. ${ }^{1}$

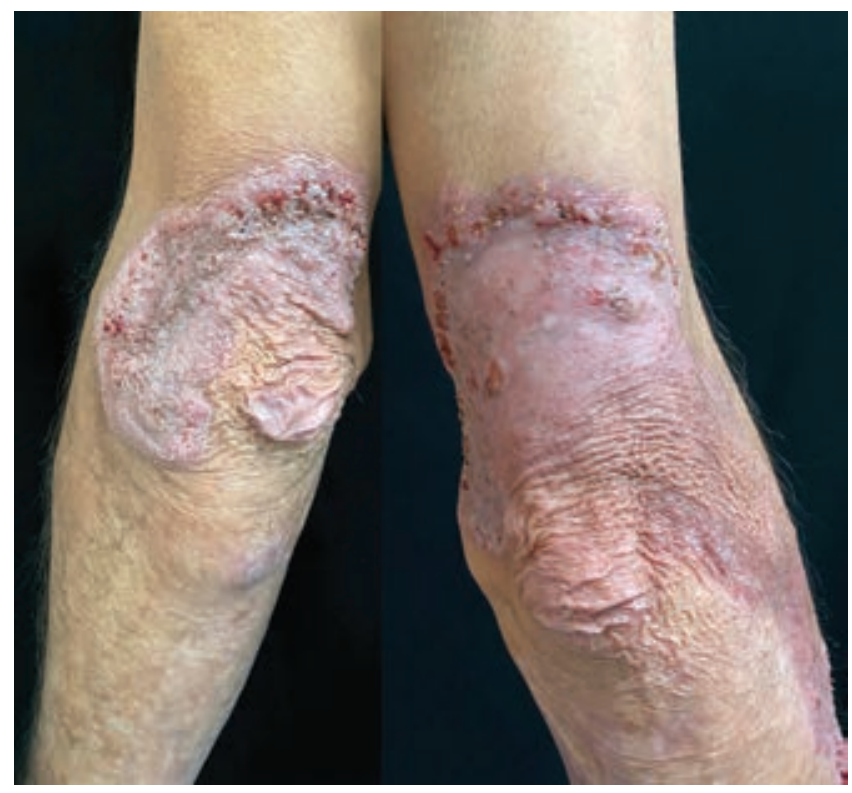

Figura 1: Extensas placas eritematovioláceas, con bordes de aspecto infiltrado, con costras hemorrágicas en ambos codos.

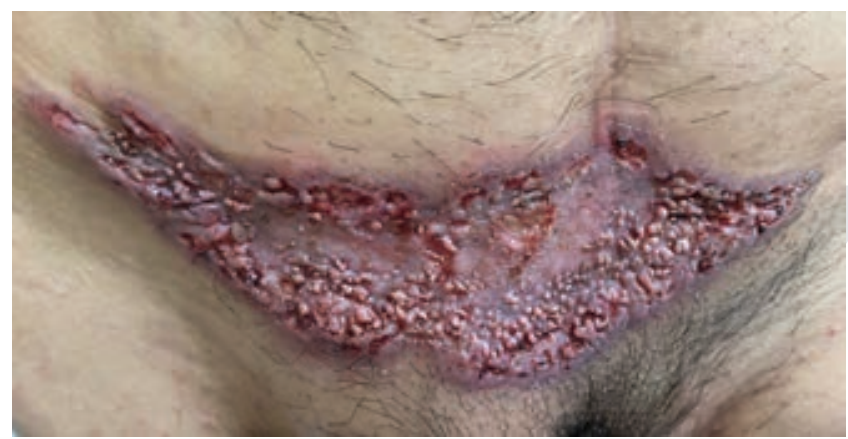

Figura 2: Gran placa eritematoviolácea, con bordes ulcerados y áreas de aspecto papilomatoso, así como atrofia central en región suprapúbica.

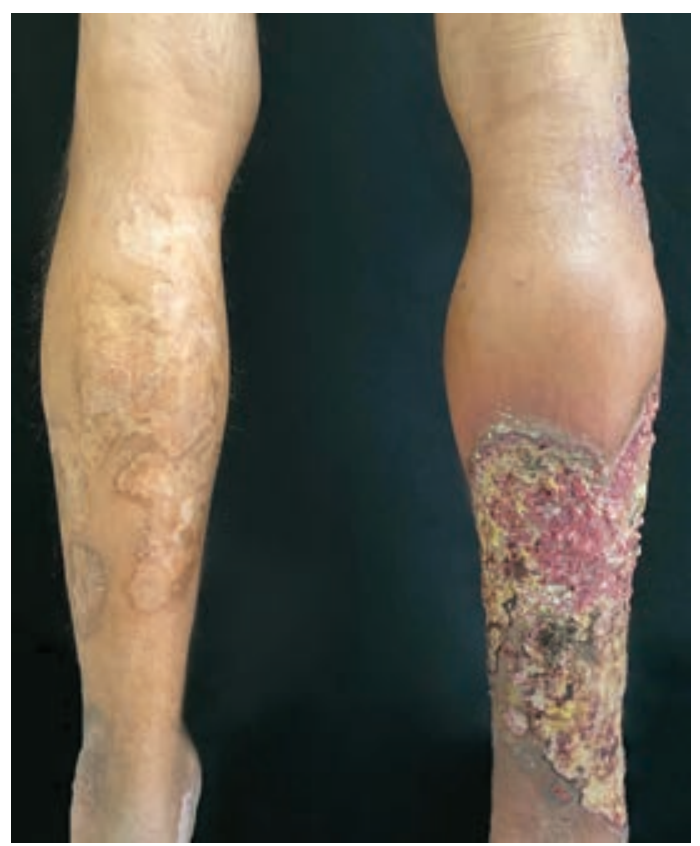

Figura 3: Cara posterior de pierna izquierda: cicatrices atróficas y manchas pigmentadas e hipopigmentadas residuales. Cara posterior de pierna derecha: extensa úlcera de bordes socavados, con tejido de granulación en la superficie y áreas queratósicas, costrosas y necróticas en algunas áreas.

Por último, el PG puede ser crónico, recurrente o autorresolutivo. Una vez que todas las lesiones hayan cicatrizado, se debe tomar una decisión sobre la duración del tratamiento, ya que algunos pacientes necesitarán terapia de por vida, mientras que otros permanecerán en remisión después de la interrupción del tratamiento. En todos los casos, se debe diseñar una estrategia de prevención o un plan de tratamiento temprano que se adapte a las necesidades de cada paciente, en especial en aquéllos para los que se planean procedimientos quirúrgicos futuros. ${ }^{1}$

En cuanto a las terapias quirúrgicas, se debe tener presente que el desbridamiento de la herida puede exacerbar las úlceras PG, por lo que está contraindicado en la mayoría de las circunstancias. Desafortunadamente, no es infrecuente que los pacientes con PG se presenten en las clínicas de dermatología con una enfermedad que progresa muy rápido después de haberse realizado este tipo de terapias. El trauma quirúrgico también puede ser el evento desencadenante que induce la aparición de una úlcera de PG. ${ }^{1}$

\section{CASO CLÍNICO}

Hombre de 52 años de edad, originario de Oaxaca y residente de la Ciudad de México, con dermatosis 
diseminada a extremidades superiores, tronco y extremidades inferiores de las primeras afecta tercio distal de brazos, codos, tercio distal de antebrazos a nivel de muñecas y dorso de manos; de la segunda región suprapúbica, cresta iliaca izquierda; de las terceras tercio inferior de muslos, rodilla izquierda y todas las caras de pierna izquierda bilateral con tendencia a la simetría. La dermatosis consistía en numerosas úlceras de bordes irregulares, de fondo limpio, de superficie con tejido de granulación blanquecino, bordes socavados y eritematovioláceos, muy dolorosas de forma espontánea, de tres meses de evolución (Figu-

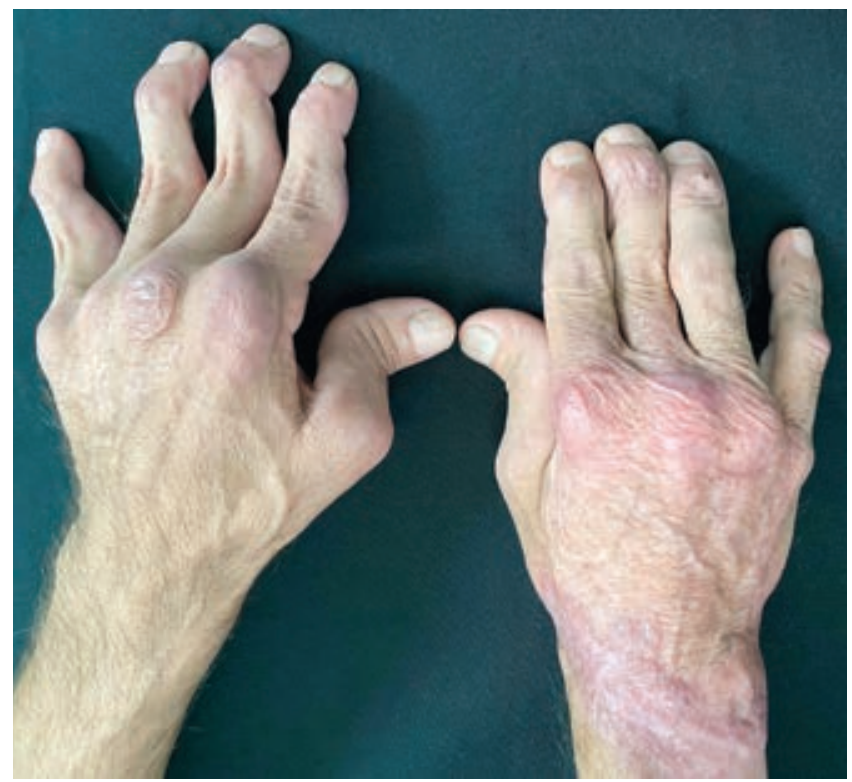

Figura 4: Deformidad de manos en cuello de cisne.

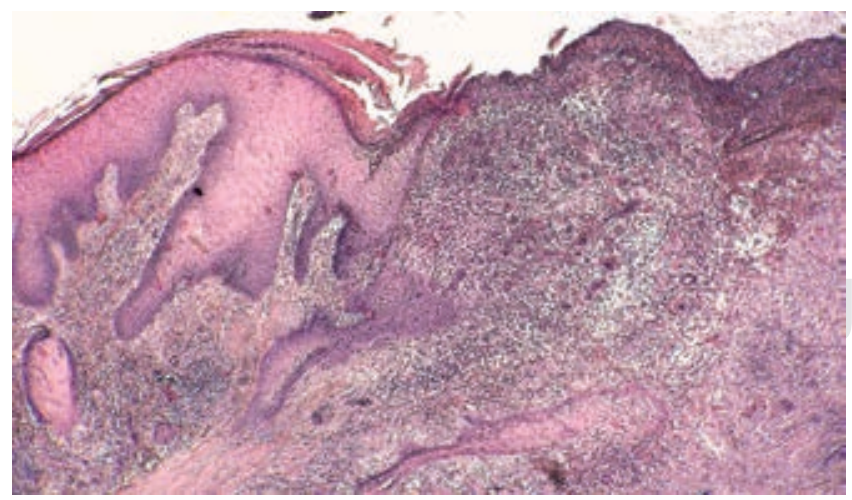

Figura 5: Epidermis con hiperplasia pseudoepiteliomatosa, acantosis regular y zonas de ulceración. La dermis presenta densa reacción inflamatoria (H\&E 4X).

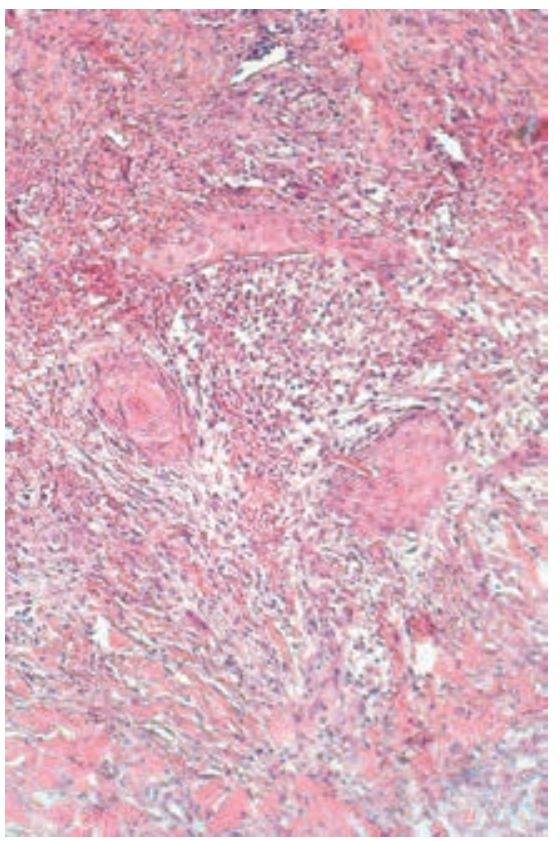

Figura 6:

Infiltrado

granulomatoso

perivascular y restos

epiteliales (H\&E 10X).

ras 1 a 3). En extremidades superiores se evidencia deformidad en cuello de cisne secundaria a artritis reumatoide (Figura 4).

Entre sus antecedentes patológicos refirió artritis reumatoide sin tratamiento de ocho años de evolución, tabaquismo con índice tabáquico de 3.75 y alcoholismo positivo a razón de 10 copas semanales hasta llegar a la embriaguez. Se solicitan estudios de laboratorio generales sin encontrarse datos relevantes, el factor reumatoide fue de 9.6. Dentro del protocolo de estudio se realizó una biopsia incisional de piel para estudio histopatológico, el cual mostró la epidermis con acantosis regular, zonas con hiperplasia pseudoepiteliomatosa, amplias zonas ulceradas. La dermis superficial, media y profunda mostró infiltrados moderadamente densos con participación de histiocitos, células gigantes multinucleadas de tipo cuerpo extraño, así como numerosos polimorfonucleares dentro y fuera de los vasos; amplias zonas de fibrosis de la colágena y focos con extravasación de eritrocitos (Figuras 5 a 7).

Con los datos anteriores se estableció el diagnóstico de pioderma gangrenoso ulceroso diseminado. El tratamiento consistió en prednisona de $1 \mathrm{mg} / \mathrm{kg}$ por dos meses con dosis reducción y azatioprina de $50 \mathrm{mg}$ cada 12 horas. Se solicitó la valoración del servicio de reumatología, debido a la asociación del pioderma gangrenoso con artritis reumatoide (Figura 8). 


\section{COMENTARIO}

En este caso se estableció el diagnóstico de pioderma gangrenoso ulceroso diseminado por correlación clínicopatológica de la dermatosis, que se distingue por úlceras y diseminación de las lesiones.

Figura 7:

Presencia de neutrófilos en la luz de los vasos (H\&E 40x).

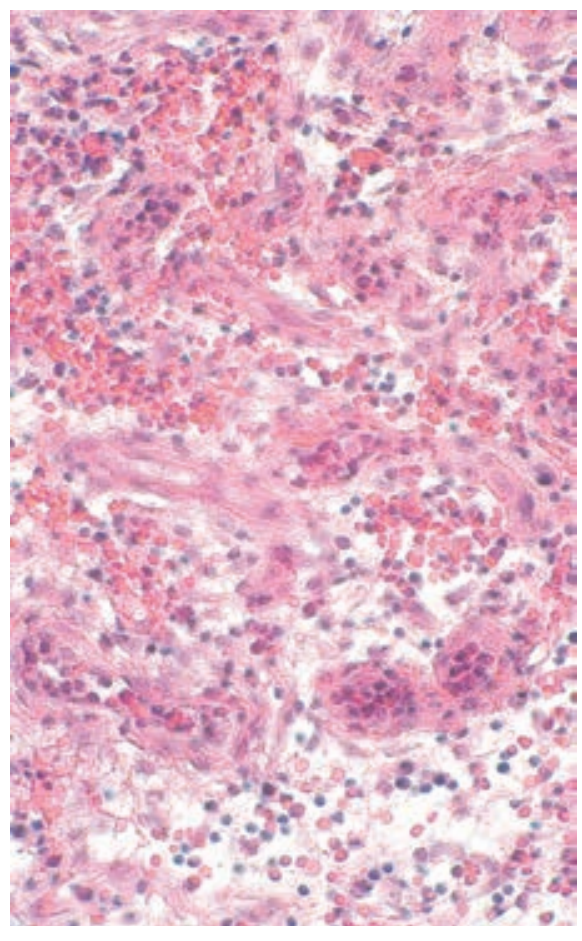

Se ha establecido una relación entre pioderma gangrenoso y artritis inflamatorias, siendo las más comunes artritis reumatoide (AR) $(50.4 \%)$, artritis asociada a enfermedad inflamatoria intestinal (10.9\%) y artritis psoriásica (8.5\%). ${ }^{9}$ Los pacientes con artritis reumatoide tienen tres veces mayor probabilidad de desarrollar pioderma gangrenoso; esta asociación es más fuerte en pacientes jóvenes, hombres y judíos. La artritis reumatoide precede al pioderma gangrenoso con una media de 9.7 años. A pesar de estos hallazgos, aún no se determina en qué medida predispone al desarrollo de pioderma gangrenoso. ${ }^{2}$ Esta ausencia de evidencia se debe a la falta de estudios de casos y controles que comparen pacientes con $P G$ y controles con respecto a la presencia de AR, así como a la falta de estudios de cohortes que den seguimiento a los pacientes con AR para detectar la aparición de PG. ${ }^{11}$

Existen otras patologías relacionadas al PG con menor frecuencia como la gammapatía monoclonal por IgA, policitemia vera y algunas neoplasias, como el linfoma no Hodgkin y la leucemia mielocítica crónica. ${ }^{12}$

La presentación extracutánea de PG es poco frecuente, y se caracteriza por infiltrados de neutrófilos que provocan la formación de abscesos estériles. Afectando principalmente a nivel ocular, óseo y pulmonar, aunque también puede involucrar el bazo, el hígado y el sistema nervioso central. ${ }^{13}$

La enfermedad sistémica subyacente se da en alrededor de $57 \%$ de los pacientes con PG. La enfer-
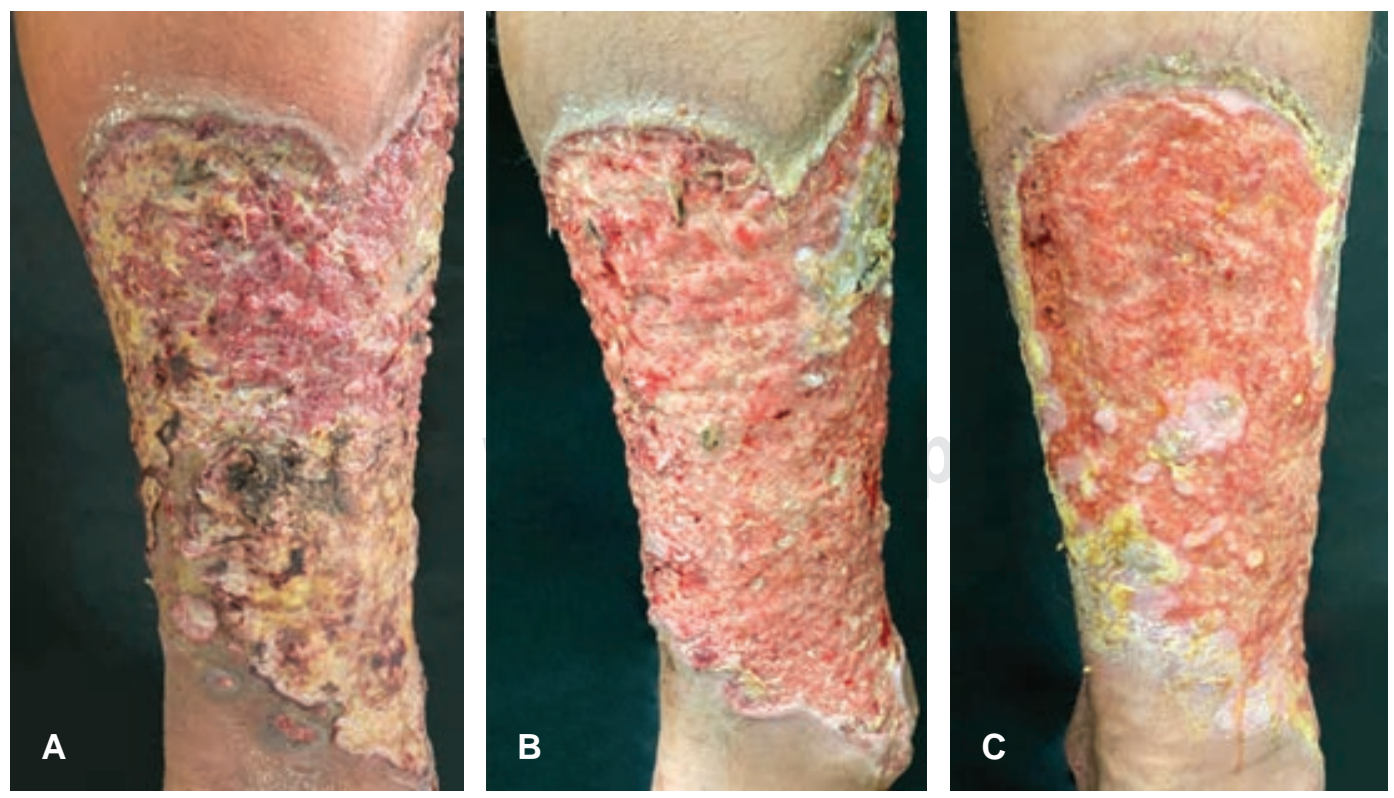

Figura 8:

Imagenes comparativas. A) Pretratamiento. B) A las dos semanas. C) A las cuatro semanas de haber iniciado el tratamiento. 
medad inflamatoria intestinal, la artritis y las neoplasias malignas hematológicas y sólidas son las principales enfermedades asociadas. ${ }^{10}$ Como dermatólogos, se deben considerar estas patologías y abordar al paciente de forma integral para tener resultados satisfactorios en el manejo.

\section{REFERENCIAS}

1. Maverakis E, Marzano AV, Le ST, Callen JP, Brüggen MC, Guenova E et al. Pyoderma gangrenosum. Nat Rev Dis Primers. 2020; 6: 81.

2. Kridin K, Damiani G, Cohen AD. Rheumatoid arthritis and pyoderma gangrenosum: a population-based case-control study. Clin Rheumatol. 2021; 40: 521-528.

3. Acosta J, Águila CR. Pioderma gangrenoso. Med Int Méx. 2014; 30: 92-98.

4. Alavi A, French LE, Davis MD, Brassard A, Kirsner RS. Pyoderma gangrenosum: an update on pathophysiology, diagnosis and treatment. Am J Clin Dermatol. 2017; 18: 355-372.

5. George C, Deroide F, Rustin M. Pyoderma gangrenosum - a guide to diagnosis and management. Clin Med (Lond). 2019; 19: 224-228.

6. Leger M, Newlove T, Chu J, Meehan S, Stein J. Pustular pyoderma gangrenosum. Dermatol Online J. 2011; 17: 17.

7. Milam EC, Brinster NK. Superficial granulomatous pyoderma of the leg improved after conservative management with Unna boot and intralesional steroid injections. JAAD Case Rep. 2018; 4: 797-799.
8. Vences CM, Malo JR, Navarrete FG. Pioderma gangrenoso ulcerado diseminado: comunicación de un caso. Dermatología Rev Mex. 2009; 53: $96-99$.

9. Sawka E, Zhou A, Latour E, Friedman M, Ortega-Loayza AG. Inflammatory arthritis-associated pyoderma gangrenosum: a systematic review. Clin Rheumatol. 2021; 40: 3963-3969.

10. Kridin K, Cohen AD, Amber KT. Underlying systemic diseases in pyoderma gangrenosum: a systematic review and meta-analysis. Am J Clin Dermatol. 2018; 19: 479-487.

11. Ashchyan HJ, Butler DC, Nelson CA, Noe MH, Tsiaras WG, Lockwood SJ et al. The association of age with clinical presentation and comorbidities of pyoderma gangrenosum. JAMA Dermatol. 2018; 154: 409-413.

12. Callen JP, Jackson JM. Pyoderma gangrenosum: an update. Rheum Dis Clin North Am. 2007; 33: 787-802.

13. Borda LJ, Wong LL, Marzano AV, Ortega-Loayza AG. Extracutaneous involvement of pyoderma gangrenosum. Arch Dermatol Res. 2019; 311: 425-434.

Correspondencia:

Dr. Juan Ramón Trejo-Acuña

Dr. Vértiz No. 464, esq. Eje 3 Sur,

Col. Buenos Aires, 06780 ,

Alcaldía Cuauhtémoc, CDMX.

Tel: 55 5519-6351

E-mail: hermesjuanderma@hotmail.com 